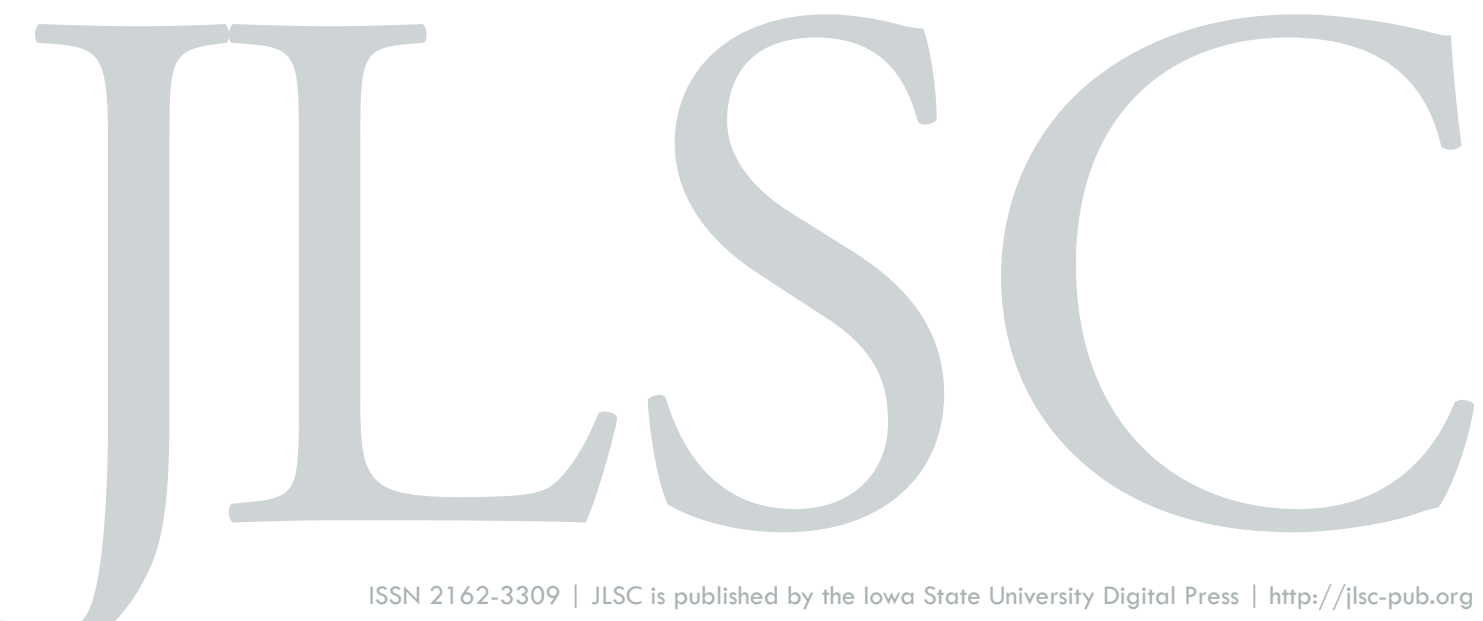

Volume 9, General Issue (2021)

\title{
Academic Librarians, Open Access, and the Ethics of Care
}

\section{Cara Bradley}

Bradley, C. (2021). Academic Librarians, Open Access, and the Ethics of Care. Journal of Librarianship and Scholarly Communication, 9(General Issue), eP2418. https://doi.org/10.31274/ilsc.12914

This article underwent fully anonymous peer review in accordance with JLSC's peer review policy. 


\title{
Academic Librarians, Open Access, and the Ethics of Care
}

\author{
Cara Bradley \\ Research \& Scholarship Librarian, University of Regina
}

This paper explores the value of applying the ethics of care to scholarly communications work, particularly that of open-access (OA) librarians. The ethics of care is a feminist philosophical perspective that sees in the personal a new way to approach other facets of life, including the political and the professional. Care, in this context, is broadly construed as "a species of activity that includes everything we do to maintain, contain, and repair our 'world' so that we can live in it as well as possible" (Fisher \& Tronto, 1990, p. 40). Joan Tronto outlined four elements of care: attentiveness, responsibility, competence, and responsiveness, and highlighted the value of care beyond the domestic sphere (1993). The ethics of care values care and relationships as instructive ways of framing and examining work, and has been applied in diverse disciplines, including education, nursing, social work, and even business. Several LIS professionals have considered the ethics of care in the context of library technologies (Henry, 2016) and digital humanities (Dohe, 2019), among others. The ethics of care can also provide inspiration for OA librarians as we think about the scope and nature of our work. What could open access librarians learn from the ethics of care? How might our practice change or evolve with the ethics of care as an underpinning philosophy? Who do we include in our circle of care while we undertake our work? The ethics of care provides a more expansive way to think about OA librarianship.

Received: $01 / 06 / 2021$ Accepted: 04/02/2021

Correspondence: Cara Bradley, 3737 Wascana Pkwy, Regina, SK S4S 0A2, Canada, cara.bradley@uregina.ca 


\section{IMPLICATIONS FOR PRACTICE}

1. The non-university public (one of the largest potential audiences for this work) are seldom the target of OA education and advocacy efforts, nor are they regular participants in conversations about the value and impact of $\mathrm{OA}$.

2. The ethics of care, a feminist framework for acknowledging relational interdependencies and valuing care, provides inspiration for librarians considering OA advocacy and education beyond the setting of the most wealthy, prestigious, and well-resourced universities.

3. Care ethics moves scholarly communication decisions beyond the personal to highlight the moral and political imperative of OA work.

\section{INTRODUCTION}

Scholarly communication practices have been a major area of concern in academia in recent years, particularly in the face of increasing funder OA mandates to improve the accessibility of academic research. Academic librarians have been actively involved since the early days of $\mathrm{OA}$, and much of the campus-wide responsibility for advocacy, education, and infrastructure development has landed squarely on the library. The role of scholarly communications librarians engaged in this work is wide-ranging; in their study of position postings, $\mathrm{Xia}$ and $\mathrm{Li}$ found that scholarly communication librarian jobs across the time period studied included requiring incumbents "to advocate open access digital scholarship, provide consultation to faculty on legal issues regarding research and publication (e.g., copyright, intellectual property, fair use, permissions), and provide support for new digital initiatives (e.g., institutional repositories and electronic journal publishing) in addition to performing some traditional library services" (2015, p. 18). Additionally, they found that the work was constantly changing, with additions like policy development, collaboration with faculty, enhanced roles in publication occurring over time. While the impact of this broad scope has most directly impacted scholarly communications librarians, it has also had an impact across academic librarian positions, challenging collections librarians to re-think their strategies, liaison librarians to address OA publication questions from faculty and graduate students, and systems librarians to create and maintain institutional repositories that facilitate deposit of scholarly work.

Perhaps unsurprisingly, the broad scope and continually changing nature of this work contributes to the well-documented increase in stress and burnout among academic librarians in general (Wood et al, 2020), and in scholarly communications librarians (Salo, 2013; Dawson, 2018; Bonn, Cross, \& Bolick, 2020). It is challenging, in a time of shrinking budgets and neoliberal agendas, to find ways to continue this important work. This paper applies the 
ethics of care to one facet of scholarly communications work, OA librarianship, to explore its potential to help conceptualize and prioritize work in a more meaningful and manageable way. While OA publishing is only one component of the complex scholarly communications ecosystem, it has been chosen as the focus of this paper because it is the area where academic libraries and librarians direct most of their attention and effort. It is also where librarians may feel that their work is particularly challenging and even futile, as it is dependent on the actions and responses of others (including researchers, publishers, granting agencies) that are outside of their own control.

To date, the vast majority of academic librarian efforts on OA have been internal, that is focused within the academy and, in many cases, even limited to their home institution. This is understandable: 1) there has been (and continues to be) a lot of work involved in supporting the shift from a centuries-old scholarly publishing model to a new and more open model and; 2) academic institutions operate within funding models and assessment frameworks that lead to competition among both academics and their institutions. However understandable, though, this internal focus is seemingly at odds with the goal of open access publishing which, at its heart, aims to extend access to scholarly work to those who wouldn't otherwise have access, a broad swath of the population that includes researchers from developing countries, academics at institutions with smaller collections budgets and fewer resources, as well as those outside academia. The non-university public (one of the largest potential audiences for this work) are seldom the target of open access education and advocacy efforts, nor are they participants in conversations about the value and impact of open access. This seems a crucial omission because it deprives the OA movement of the powerful voices of citizens and residents who stand to benefit from the research that many of them have in fact funded through government grants and publicly-funded universities. Academic librarians (and researchers within their institutions) would benefit from increased interest and readership for their work, and might find that increased public awareness of the issues would lead to more individual and community advocacy towards funders, institutions, researchers, and legislators for furthering OA uptake. The advantages to academic librarians and researchers are in addition to the potential social, health, education, and economic benefits that increased access to scholarly research presents for the wider public. This paper explores the ethics of care as a potential framework to inspire and guide this work.

\section{THE ETHICS OF CARE}

The notion of an ethic of care emerged in the 1970s and 1980s from feminist scholars including Carol Gilligan, Nel Noddings, and Virginia Held. Hankivsky (2014) characterizes these scholars as part of the "first generation" of "care theorizing . . . whose earliest articulations ... were linked to women's morality and in particular mother, caring, and nurturing 
activities and experiences" (Hankivsky, 2014, p. 253). Second generation theorists, led by Joan Tronto, have expanded considerably on the scope of the ethics of care, emphasizing that, while care has often traditionally been "women's work," there is nothing inherently gendered about caring. This is evidenced in Tronto and Fisher's definition of care as "a species activity that includes everything that we do to maintain, continue and repair our 'world' so that we can live in it as well as possible" (Tronto, 1993, p. 103). Defining care in this way makes it more much more difficult to dismiss (as it has been throughout its history of being exclusively associated with women) and instead centers the relationships and dependencies of life in a way that demands attention.

The central tenet of the ethics of care is that caring relationships are fundamental throughout the human life span. Although caring relationships are most evident in relationships with family and close friends, they should also be extended into society's social and political structures. The relations will not be exemplified in the same kind of deeply involved caring activities as when a parent cares for a child, but caring social relations even in the political and legal domains will share some of the features of caring relations in the family or among friends. (Held, 2006, p. 130)

This relational conceptualization of human nature and experience is in contrast to traditional moral theories, which privilege the notion of independent and autonomous individuals. The ethics of care rejects this idea of the self-made person who only works cooperatively in instances where it is clearly in their personal interest, seeing this worldview as a tool "adopted by the dominant moral theories [to] provide moralities best suitable for legal, political, and economic interactions between relative strangers" (Held, 2006, p. 14). Further, the ethics of care requires not only positioning care and relational dependencies as central tenets of human life, whether in the personal, social, legal, or political arenas, but also demands that caring work be valued. This work, traditionally undertaken by women and racial minorities, has often been overlooked in favour of maintaining the myth of the self-sufficient individual, thereby serving to deny carers a share in the rewards arising from their work. Thus defined, it becomes clear than an ethic of care is a way of being in and seeing the world. It calls us to attend to the relationships and interdependencies that underpin all human activity-Kittay calls these "nested dependencies" (2011, p. 56) —and it requires that this awareness lead to and guide action. In doing so, it "hold[s] possibilities as a means toward equitable, inclusive, anti-neoliberal futures" (Higgins, 2017, p. 73).

\section{APPLICATION OF THE ETHICS OF CARE}

Given its focus on care and its origins in feminist studies, it is perhaps unsurprising that care ethics have been applied to numerous female-dominated fields, including education 
(Noddings, 1984), social work (Meagher \& Parton, 2004), and nursing (Nortvedt, 2011). However, with the development of so-called "second wave" theorizing, the ethics of care is now being applied to other fields that are not traditionally "women's work," including engineering (Campbell \& Wilson, 2017), business (Hamington $\&$ Sander-Staudt, 2011), and law (Herring \& Feenan, 2017). The application of care ethics has expanded and "now extends from the moral to the political realm, from personal to public relationships, from the local to the global, from feminine to feminist virtues and values, and from issues of gender to issues of power and oppression more generally" (Koggel \& Orme, 2010, pp. 109-110).

The ethics of care has also been adopted by scholars as a framework to theorize about academic work. In one example, Mountz and her geography colleagues evoke "feminist care ethics" to underpin the slow and "care-full scholarship" needed to counter the speed and quantification demanded by the neoliberal academy (Mountz et al., 2015, pp. 1239; 1245). They advocate for building a foundation of self-care upon which it is then possible to develop the caring community needed in academia, viewing this as a "political activity when we are situated in institutions that devalue and militate against such practices" (Mountz et al., 2015, p. 1239). Their embrace of the ethics of care also leads to calls for this care to extend beyond the walls of academia to include activism, advocacy, and research within the broader community.

Academic librarians have also invoked the ethics of care in reflecting on the nature of their work. Dohe (2019) describes the growing disconnect in digital library work between (primarily male) technical teams and the (mostly female) librarians on the frontlines of content and user work. She notes that "design discussions" frequently "privilege the discussion of objects and data over people - the pursuit of a more perfect object model without centering and clearly articulating the user's needs" (Dohe, 2019, Whose Community Projects section, para. 5). She traces this disconnect from its origins in the separation and gendering of digital library positions, through its impact on personal relationships and communication, and on to its limiting effect on the usability and impact of digital library projects that may achieve technical perfection but fail to consider user needs. She asserts that:

If we continue to privilege coding over care as if the two are fully disconnected, and hand the reins of what should be our most intentional and accessible applications to a homogenous cohort of well-intentioned but isolated decision makers who are removed from direct and constant care work for end users or colleagues, then we are complicit in the neoliberal hollowing of the academic library mission to use our resources for the public good. (Dohe, 2019, Care in Our Home Institutions section, para. 1) 
Her suggestion in response to this state of affairs is to invoke the ethics of care, as described by Tronto, in order to (among other things) rethink our use of quantitative metrics, conduct research in concert with and consult with users, and equally value all aspects of digital library work. Dohe sees that only this will return us to the "truly radical roots of digital libraries" (2019, Introduction section, para. 3) and allow us to realize their potential to meaningfully expand access to information and contribute to human betterment.

For those with an interest in scholarly communication, current efforts to infuse the ethic of care into the production side of the publishing process are particularly thought-provoking. The Radical Open Access Collective, started in 2015, is a community of like-minded presses, journals, and OA projects that aims to remake scholarly publishing around openness, critique of the status quo, experimentation, underrepresented cultures of knowledge, and, most germane to this paper, an ethic of care (Radical Open Access Collective, n.d.). In contrast to mainstream scholarly publishing, with its strong commercial interests, exploitation of academic labour, and its privileging of questionable metrics, the Radical OA Collective views publishing as "a relational practice, highlighting and caring for the relationships involved throughout the publishing process" (Adema \& Moore, 2017, Ethics of Care section, para. 1). OA publishing is seen as "a form of care" with "the potential for developing publishing practices that enrich not just the careers of individual scholars but also communities" (Moore, 2018, pp. 4-5). In practical terms, this ethic of care in publishing is manifested in collaboration and mutual support for publishing projects among the Collective's members, as well as an emphasis on the people involved in the publishing process and attention to the relationships among them.

Because the Collective's memberships consists of publishers, its emphasis is on relationships among those involved in content creation-from publishers, authors, editors, reviewers, etc. But what if we, as librarians involved in OA, were to extend this emphasis on care and relationships to the dissemination and distribution of scholarly work? In the introduction to a past special edition of this journal, Shorish wrote of the importance of librarians "situating their scholarly communication work within the frame of an equitable and democratic society" in order to understand "What are the challenges and the opportunities? Where are we making progress? Where is there disenfranchisement?" (2018, p. eP2257). The ethics of care offers one way to critically interrogate OA librarianship. Might our work, not unlike that of the OA Collective, be infused with an ethic of care and, in fact, become a more conscious enactment of care that extends beyond our individual institutions?

\section{FOUR PHASES AND IMPLICATIONS FOR OPEN ACCESS LIBRARIANS}

Joan Tronto divides care into four discrete but connected phases that are useful for analyz- 
ing specific types of work in light of an ethic of care. She is clear that these phases (attentiveness, responsibility, competency, and responsiveness) are not limited to our care for family and close friends but "can also inform our practices as citizens. They direct us to a politics in which there is, at the center, a public discussion of needs" and a "discussion of the issues of public life from a vision ... of interdependent actors, each of whom needs and provides care in variety of ways" (Tronto, 1993, p. 168). Each of these four phases provides insight into how open access librarians might embrace an ethic of care to expand their practice to include the wider community beyond academia.

Attentiveness, the first phase in Tronto's model, is "caring about," that is, recognizing the existence of a care need and "making an assessment that this need should be met" (1993, p. 106). The central argument of this paper is that there is an unmet need to make scholarly communication more inclusive and community-centred. This stance echoes that which emerges from ACRL's recently published scholarly communication research agenda which, while it only directly mentions the ethics of care once (p.35), is unequivocal in calling for equity and social justice to underpin OA work. As already mentioned, other academic librarians like Dohe have written briefly about this need, but as a profession we have thus far largely failed to, in Tronto's language, attend to or care about this need in a meaningful way. Care ethics prompts us to take this step; it "forces us to think concretely about people's real needs, and about evaluating how these needs will be met, it introduces questions about what we value into everyday life" (Tronto, 1993, p. 124). Thinking along these lines leads to questions about the needs of the public with respect to accessing scholarly research. Limiting our OA work to within academia leaves those outside of our institutions with little guidance, education, and support in accessing scholarly work.

Dohe's lament about digital library work is instructive in considering scholarly communication when she writes that it "has become a re-enactment of local power dynamics that privilege wealth, whiteness, and masculinity at the expense of meaningful inclusive practice and care work" (2019, In Brief section, para. 1). Does our focus on OA as an academic issue reinforce social hierarchies (an academic elite) and overlook the very needs that OA was envisioned as meeting? Academic librarians undoubtedly care about supporting academics and their publishing decisions, but is focus on these relationships ignoring other, broader needs? Tronto's general observation seems to speak almost directly to this issue when she writes that:

The promising scenario of a politics of care, then, requires that we think about care in its broadest possible public framework. It requires that care's focus on needs change the content of our public discussion so that we talk about the needs of all humans, not just those who are already sufficiently powerful to make their 
needs felt. It requires a recommitment to democratic processes . . . . It requires a hard look at justice, as we determine which needs to meet. (1993, p. 170)

OA publishing holds the potential to exemplify the act of caring, but a disconnect exists between intent and outcome, between the goal of more accessible research and the actual access, use, and understanding of OA among the broader public. Academic librarians have the knowledge and expertise to, in Tronto's words, attend to and care about this need.

Tronto's second phase is responsibility, or "taking care of," and entails "assuming some responsibility for the identified need and determining how to respond to it" (1993, p. 106). Inherent in this phase is recognition that one has a role to play in meeting the identified need, and that caring includes not only engagement with issues and concerns beyond the self but also results in concrete action. One particularly relevant example of a thoughtful application of the ethics of care is the work of the "Information Maintainers," a loosely affiliated group of caring individuals drawn from diverse professions, including but certainly not limited to librarians, who work to "sustain bodies of information, information systems, and the communities that support them." (The Information Maintainers, 2019, p. 8). The ethics of care is the lens through which they explore and articulate the importance of relationships in their work, as well as their commitment to interrogating power and exposing injustice. The Information Maintainers foundational document (2019) and their community-building work could serve as a model for future OA and scholarly communications work in the context of the ethics of care.

Assuming responsibility for identified needs inevitably raises questions of capacity to take on this work, both as individuals and as a profession; for many academic librarians, educating and advocating for OA outside of academia might seem like one task too many. The ethics of care, though, invites us to think about the prioritization of these many tasks, and to find strength in a like-minded community, much as the Information Maintainers are doing. The caring work of our jobs is often the least valued of our contributions, particularly that caring directed to the less privileged. The ethics of care seeks to prioritize this care work, make it visible, and to increase the value assigned to it. Once this happens, it is possible to see broader OA work by academic librarians in a new light and to reassign it a greater priority in our workload. The need to challenge power relations and highlight the political dynamics of the scholarly communication market gain increasing prominence and open the door to new ways of dismantling neoliberal journal publishing systems, such as Ghamandi's "New Fair Deal" (Ghamandi, 2018, p. 11). Ideally, the privileging of this type of important care work, as demanded by an ethic of care, would see it rise in importance in relation to some of our other work, which would fall away. 
Competency is the third phase in Tronto's conceptualization of care, and requires direct engagement and work with those receiving care; she also refers to this as the "care-giving" phase (1993, p. 107). This phase shifts the focus from thought to action and is "a way of making highly abstract questions about meeting needs return to the prosaic level of how these needs are being met" (Tronto, 1993, p. 124). In terms of OA, it challenges us to transform our ideals about wider access to scholarly research into action. This is where the hard work happens, and it can be daunting to think of the challenge it presents. Tronto is realistic in acknowledging that good care requires resources-whether these be time, materials, or skills (1993, p. 110) and also reminds us that distribution of resources to caring work is a conscious (and political) choice.

It is also important to note that the work involved in adopting a broader mandate with respect to OA needn't not fall too heavily on individuals. Instead, a combination of individual and collective effort could create meaningful change in this area. Nowviskie notes that fatigue is a known hazard in care work and that scholars of care ethics "posit the value of 'networks of care' as a way for the practice to leverage its own strengths toward the increase of capacity and resilience at a personal and systems level" (2015, An Ethic of Care section, para. 10) without burning out the carers. The Radical Open Access Collective is an example of this model, where both individuals and the collective engage in care work to advance change. The Collective emphasizes the relationships that underpin the best in scholarly publishing and amplifies the impact of its members. SPARC (the Scholarly Publishing and Academic Resources Coalition) similarly coordinates the actions of many (primarily academic libraries) to advance open access to research and educational resources by harnessing collective action to maximize individual efforts. Other efforts by academic librarians to expand the OA community to include relationships with public librarian partners as well as citizens could also amplify the impact of our work. This shift would also lay bare and provide a means for challenging existing hierarchies and power structures. In this way, a moral imperative to care also "connect[s] our broadest political and social aspirations with the consequences and effects of our actual practices" (Tronto, 1993, p. 124). The ethics of care provide a bridge between our practice and the political.

Tronto's fourth phase is responsiveness, which she also calls "care receiving," as it "recognizes that the object of care will respond to the care ... [and] it is important to include care-receiving as an element of the caring process because it provides the only way to know that caring needs have actually been met" (1993, pp. 107-8). This is an important phase for academic librarians engaged in OA work and encourages a renewed focus on the users of open access research. A great deal of current effort is focused on systems and processes (e.g. institutional repositories, submission workflows, journal publishing systems) without due consideration of the broader public. We don't know if members of the public know 
anything about accessing and evaluating OA publications, and whether our current systems facilitate discovery and learning by the larger population. Dohe echoes this concern in her analysis of digital library work when she notes a "fundamental disconnect between developers of these applications and the front line users who must navigate, curate, and use the contents of such systems" and the "pursuit of a more perfect object model without centering and clearly articulating the user's needs" (2019, Whose Community Project section, para. 5). This isn't to suggest that all user needs are ignored; systems and processes are developed with due attention to faculty/researcher needs, but the non-academic perspective is often lost in favour of that of content producers.

The notion of responsiveness (or a disappointing lack thereof) is perhaps most acutely felt by academic librarians working with students nearing graduation. Our students (or care receivers in Tronto's language) become accustomed to the care (in the form of access) that they receive from their academic library but upon graduation, they typically lose access to the quality resources that they learned to use and rely on as students. A recent Project Information Literacy study surveyed over 1600 recent graduate from ten universities and colleges and found that $73 \%$ reported difficulty finding affordable resources, and $50 \%$ lamented loss of access to the resources that they had used while students. (Head, 2016). The ethics of care provides a framework for thinking about this state of affairs, understanding why this forced unresponsiveness on the behalf of academic librarians feels so terribly disappointing (both to librarians and students), and provides ideas for how to improve the situation. Engaging in advocacy and education about OA beyond academia is one way that academic librarians can engage in the continuation of the care that they exhibit in their daily work with university students, increasing their responsiveness and improving the care receiver's experience.

\section{CARE-BOTH MORAL AND POLITICAL}

Tronto emphasizes that, while valuing care is a moral process, it is also a political activity. She writes that, "[c]are becomes a tool for critical political analysis when we use this concept to reveal relationships of power" (1993, p. 170). As its root, care ethics highlights social justice issues, raising important questions about inequalities, both individual and structural. The ethics of care challenges us to think about systems, our place within them, and how we might challenge them. Tronto writes of the "privileged irresponsibility" (1993, p. 121) of those who uphold and benefit from these systems with inadequate care for those who do not. This provides a new way to think about our role as academic librarians in the scholarly publishing system. We have privileged access to scholarly research in a way unparalleled by those outside of academia, and we also have powerful voices (though perhaps sometimes not as powerful as we would like!) in the scholarly publishing arena. Many of our fellow 
citizens do not share this empowering access to scholarly research and, much as women, racial minorities, and those with lower incomes are disproportionately impacted by the undervaluing of their caring roles, so too do race and class dynamic plays out in access to scholarly research. Whites and those from higher income homes are more likely to attend post-secondary education (Dahill-Brown, Witte, \& Wolfe, 2016; Frenette, 2007) and as a result have increased access to scholarly research during their studies. Both universityeducated and white citizens also earn higher post-graduation incomes, better positioning them to purchase access to academic articles if necessary. The result is that non-white and lower income citizens have less access to scholarly research and are less likely to benefit from its findings. This injustice is clearly both moral and political.

\section{CONCLUSION}

In writing about embracing the feminization of librarianship, Higgins expressed hope that, "a feminist care ethic may enable us to center the collaborative, communal, and politicallyengaged-ness of library work." (2017, p. 83). Similarly, the ethics of care provides a new way to think about the work of OA librarianship. It reminds us that care work matters and must be valued. It encourages us to think about who we include and who we exclude in our circle of care as we engage in OA education and advocacy efforts. Tronto's four phases-attentiveness, responsibility, competency, and responsiveness-provide a framework for widening that circle of care to include those who may in fact derive the largest benefit from more open publishing practices. The ethics of care also provides a way to conceptualize and communicate the political nature of the scholarly publishing system. Finally, it provides a touchpoint for connecting with important reconceptualizations of scholarly publishing emerging from likeminded colleagues such as the Radical Open Access Collective. By allowing an ethic of care to underpin our work as OA librarians, we can connect with work already underway on the content creation side of the public process to extend this care to a widening circle of readers and users of scholarly publications. While this article has primarily focused on OA librarianship, many other aspects of scholarly communications work may also benefit from application of the ethics of care. In addition to the inequities surrounding information $a c$ cess, the production of scholarly work is fraught with injustice, as is evidenced in discussions of issues like read and publish deals, article processing charges, author rights, citation bias, and privileging of English language publications. The ethics of care offers a holistic, careinformed, view of scholarly publishing has the potential to create a more humane and just scholarly communication system. 


\section{REFERENCES}

Adema, J., \& Moore, S. A. (2017). The Radical Open Access Collective: Building alliances for a progressive, scholar-led commons [blog post]. Retrieved from https://blogs.lse.ac.uk $\underline{\text { impactofsocialsciences/2017/10/27/the-radical-open-access-collective-building-alliances-for-a }}$ -progressive-scholar-led-commons/

Association of College and Research Libraries. (2019). Open and Equitable Scholarly Communications: Creating a More Inclusive Future. Prepared by Nancy Maron and Rebecca Kennison with Paul Bracke, Nathan Hall, Isaac Gilman, Kara Malenfant, Charlotte Roh, and Yasmeen Shorish. Chicago: Association of College and Research Libraries. https://doi.org/10.5860/acrl.1

Bonn, M., Cross, W., \& Bolick, J. (2020). Finding our way: A snapshot of scholarly communication practitioners' duties \& training. Journal of Librarianship \& Scholarly Communication, 8(1), eP2328. https:// doi.org/10.7710/2162-3309.2328

Campbell, R. C., \& Wilson, D. (2017). Engineers' responsibilities for global electronic waste: Exploring engineering student writing through a care ethics lens. Science and Engineering Ethics, 23(2), 591-622. https://doi.org/10.1007/s11948-016-9781-2

Dawson, D. (2018). Effective practices and strategies for open access outreach: A qualitative study. Journal of Librarianship and Scholarly Communication, 6(1), eP2216. https://doi.org/10.7710/2162 $-3309.2216$

Dohe, K. (2019, Feb. 20). Care, code, and digital libraries: Embracing critical practice in digital library communities. In The Library With The Lead Pipe. Retrieved from http://www.inthelibrarywiththeleadpipe. org/2019/digital-libraries-critical-practice-in-communities/

Dahill-Brown, S. E., Witte, J. F., \& Wolfe, B. (2016). Income and access to higher education: Are high quality universities becoming more or less elite? A longitudinal case study of Admissions at UW-Madison. The Russell Sage Foundation Journal of the Social Sciences: RSF, 2(1), 69-89. https://doi .org/10.7758/RSF.2016.2.1.04

Fisher, B., \& Tronto, J. (1990). Towards a feminist theory of care. In E. Abel \& M. Nelson (Eds.), Circles of care: Work and identity in women's lives. (pp. 36-54). Albany, NY: State University of New York Press.

Frenette, M. (2007). Why are youth from lower-income families less likely to attend university? Evidence from academic abilities, parental influences, and financial constraints. Ottawa: Statistics Canada. Retrieved from https://www150.statcan.gc.ca/n1/en/pub/11f0019m/11f0019m2007295-eng

.pdf?st $=62 \mathrm{yAxO} 6 \mathrm{~F}$

Ghamandi, D.S. (2018). Liberation through cooperation: How library publishing can save scholarly journals from neoliberalism. Journal of Librarianship and Scholarly Communication, 6(2), eP2223. https:// doi.org/10.7710/2162-3309.2223

Hamington, M., \& Sander-Staudt, M. (2011). Applying care ethics to business. New York: Springer. https:// doi.org/10.1007/978-90-481-9307-3 
Hankivsky, O. (2014). Rethinking care ethics: On the promise and potential of an intersectional analysis. The American Political Science Review, 108(2), 252-264. https://doi.org/10.1017/S0003055414000094

Head, A. J. (2016). Staying smart: How today's graduates continue to learn once they complete college. Seattle: University of Washington Information School. https://doi.org/10.2139/ssrn.2712329

Held, V. (2006). The ethics of care: Personal, political, and global. Oxford: Oxford University Press. Higgins, S. (2017). Embracing the feminization of librarianship. In S. Lew and B. Yousefi (Eds.), Feminists among us: Resistance and advocacy in library leadership (pp. 67-89). Sacramento: Library Juice Press. Retrieved from https://inspire.redlands.edu/oh chapters/55

Herring, J., \& Feenan, D. (2017). Compassion, ethics of care and legal rights. International Journal of Law in Context, 13(2), 158-171. https://doi.org/10.1017/S174455231700009X

The Information Maintainers [Devon Olson, Mark A. Parsons, Juliana Castro, Monique Lassere, Dawn J. Wright, et al.]. (2019)._Information maintenance as a practice of care. https://doi.org/10.5281 $\underline{\text { zenodo. } 3236410}$

Kittay, E.F. (2011). The ethics of care, dependency, and disability. Ratio Juris 24(1), 49 -58. https://doi .org/10.1111/j.1467-9337.2010.00473.x

Koggel, C., \& Orme, J. (2010). Care ethics: New theories and applications. Ethics and Social Welfare 4(2), 109-14. https://doi.org/10.1080/17496535.2010.484255

Meagher, G., \& Parton, N. (2004). Modernising social work and the ethics of care. Social Work and Society 2(1), 10-27. Retrieved from https://ejournals.bib.uni-wuppertal.de/index.php

Moore, S. (2018). Introduction. In Eds. J. Deville, S. Moore, T. Nadim (Eds.), The commons and care (p.4). http://dx.doi.org/10.17613/M6901ZF54

Mountz, A., Bonds A., Mansfield B., Loyd J., Hyndman, J., Walton-Roberts, Basu, R., Whitson, R., Hawkins, R., Hamilton,T. Curran, W. (2015). For slow scholarship: A feminist politics of resistance through collective action in the neoliberal university. ACME: An International Journal for Critical Geographies 14(4), 1235-59. Retrieved from https://www.acme-journal.org/index.php/

Noddings, N. (1984). Caring: A feminine approach to ethics and moral education. Berkeley: University of California Press.

Nortvedt, P. (2011). Guest editorial. Nursing Ethics 18(2), 147-148. https://doi.org/10.1177 10969733010393072

Nowviskie, B. (2015, Oct. 4). On capacity and care [blog post]. Retrieved from http://nowviskie.org 12015/on-capacity-and-care.

Henry, L. R. (2016). Library technologies and the ethics of care. Journal of Academic Librarianship, 42(3), 284-285. https://doi.org/10.1016/j.acalib.2016.03.013 
Radical Open Access Collective. (n.d.). Philosophy. Retrieved from http://radicaloa.disruptivemedia .org.uk/philosophy/

Salo, D., (2013). How to scuttle a scholarly communication initiative. Journal of Librarianship and Scholarly Communication, 1(4), eP1075. https://doi.org/10.7710/2162-3309.1075

Shorish, Y., (2018). Special issue: The role of scholarly communication in a democratic society. Journal of Librarianship and Scholarly Communication, 6(2), eP2257. https://doi.org/10.7710/2162 $\underline{-3309.2257}$

Tronto, J. (1993). Moral boundaries: A political argument for an ethic of care. New York: Routledge.

Wood, B.A., Guimaraes, A.B., Holm, C.E., Hayes, S.W., \& Brooks, K.R. (2020). Academic librarian burnout: A survey using the Copenhagen Burnout Inventory (CBI). Journal of Library Administration, 60(5), 512-531. https://doi.org/10.1080/01930826.2020.1729622

Xia, J. \& Li, Y. (2015). Changed responsibilities in scholarly communication services: An analysis of job descriptions. Serials Review, 41(1), 15-22, https://doi.org/10.1080/00987913.2014.998980 